\title{
ВИЗНАЧЕННЯ ШВИДКОСТІ ДЕТОНАЦІЙНОЇ ХВИЛІ У ВИБУХОВІЙ ГАЗОВІЙ СУМІШІ
}

\author{
М.М. ПОЛАТАЙКО
} УДК 534.222 .2
(C)2012

(Вул. Грушевсъкого, 180, с. Назавизів, Надвірнянский р-н, Івано-Франківсъка обл. 78425,

Україна; e-mail: pmm. miron@ mail.ru)

\begin{abstract}
У науковій літературі загальновідомою є формула швидкості плоскої детонаційної хвилі, що виведена із системи рівнянь Гюгоніо, проте для сферичного реактора користуватися нею важкувато. Метою роботи стало показати можливість втілення положень теорії вибуху в реагуючих газових середовищах для виводу подібної формули, використовуючи спеціальну модель переходу вибухової хвилі в детонацію. Як і в першому, так і в другому випадку діють закони збереження імпульсу, маси і енергії, тому результати мають бути однаковими або майже однаковими, що і підтвердили розрахунки. Таким чином, отримано формулу дуже просту для користування і більш придатну для вивчення граничних процесів об'ємної детонації.
\end{abstract}

\section{1. Вступ}

Сильний вибух малого об'єму в детонуючій газовій суміші добре вивчено в сучасній фізиці $[1,2]$. Швидкість детонаційної хвилі у сферичному реакторі мо-

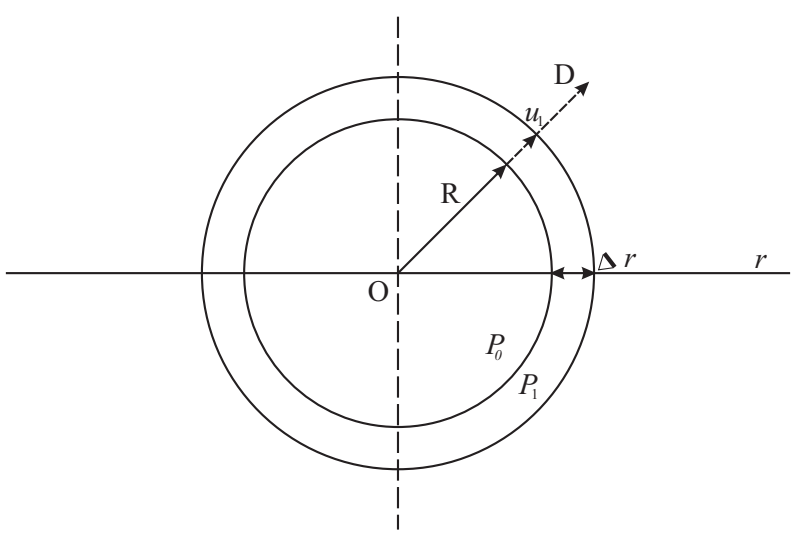

Рис. 1. Схематичне зображення ударної хвилі від точкового вибуху же бути абсолютно точно розрахована за допомогою цілої низки оригінальних програм [3]. Є і апроксимаційні формули

$\frac{D}{D_{n}}=1-\frac{A}{r-R_{x}}$,

де $r$ - поточне значення радіуса, $R_{x}$ - критичний радіус, $A$ - стала, $D_{n}$ - швидкість плоскої хвилі, $D$ швидкість сферичної хвилі. Для великих зарядів на радіусі, більшому за критичний, використовують залежність Ейрінга:

$\frac{D}{D_{n}}=1-\frac{A}{r}$.

Автор пропонує споглянути на розвиток процесу у той момент, коли енергія точкового вибуху еквівалентна енергії згорілого газу $r=R_{x}$, але $R_{x} \neq \infty$, тобто вивчити початковий етап детонації в реагуючих газових середовищах, визначивши скалярне значення швидкості детонаційної хвилі.

\section{2. Вибух у хімічно інертній суміші газів}

Розглянемо вибух у хімічно інертній суміші газів. Нехай в ідеальному газі щільністю $\left(\rho_{0}\right)$ миттєво відбувається точковий вибух. Від точки енерговиділення по газу поширюється ударна хвиля. Розглянемо стадію процесу поширення ударної хвилі, коли її амплітуда ще настільки висока, що можна знехтувати початковим тиском газу $\left(P_{0}\right)$. Це припущення рівносильне нехтуванню початковою внутрішньою енергією газу, у порівнянні з енергією вибуху, тобто маємо справу з сильним вибухом. Завдання полягає у визначенні швидкості вибухової хвилі, коли фронт моделюється 
жорстким поршнем, наминаючим на себе газовий об'єм, що знаходиться попереду (рис. 1). Основні закономірності цього процесу загальновідомі [4], існує простий наближений метод їх встановлення.

Припустимо, що вся маса газу, охопленого вибуховою хвилею, зібрана в тонкий шар на поверхні фронту, щільність в якому стала і дорівнюе щільності на фронті:

$\rho_{1}=\frac{\gamma+1}{\gamma-1} \rho_{0}$

(цю формулу можна отримати із формули для сильних ударних хвиль [5], коли $(M)$ - число Маха, набагато більше за одиницю). Щоб уникнути непорозумінь, відзначимо, що в даному випадку відображається перехід середовища з індексом (0) у середовище 3 індексом (1), де (0) - нерухоме середовище перед початком вибуху. Товщина шару $\Delta r$ визначається з умови збереження маси:

$4 \pi R^{2} \Delta r \rho_{1}=\frac{4}{3} \pi R^{3} \rho_{0}$,

звідки маємо

$\Delta r=\frac{R}{3} \frac{\rho_{0}}{\rho_{1}}=\frac{R}{3}\left(\frac{\gamma-1}{\gamma+1}\right)$.

Оскільки шар дуже тонкий, швидкість у ньому майже не змінюється і збігається зі швидкістю газу на фронті:

$u_{1}=\frac{2 D}{\gamma+1}$

точніше в теорії ударних хвиль розглядається формула, що зв'язує швидкість течії газу $\left(u_{1}\right)$ за фронтом ударної хвилі зі швидкістю фронту $(D)$ :

$u_{1}=\frac{2 D}{(\gamma+1)\left[1-\left(c_{0} / D\right)^{2}\right]}$

де $c_{0}$ - швидкість звуку в нерухомому газі. Маса у шарі скінченна величина і дорівнює масі $(m)$, що знаходилася спочатку в сфері радіусом $(R)$ :

$m=\frac{4}{3} \pi R^{3} \rho_{0}$

Позначимо тиск на внутрішній стороні шару $\left(P_{c}\right)$, нехай він становить частку $(\alpha)$ від тиску на фронті хвилі. Запишемо другий закон Ньютона:

$\frac{d}{d t}\left(m u_{1}\right)=4 \pi R^{2} P_{c}=4 \pi R^{2} \alpha P_{1}$
Рівняння застосовується для шару завтовшки $(\Delta r)$. Воно може бути використано тільки в межах, коли

$0<R \leq R_{x}^{0}$

де $R_{x}^{0}$ - визначається з енергетичних міркувань. У цій точці кінетична енергія вибухової хвилі ще досить велика і їі швидкість значно перевершуе швидкість звуку в нерухомому газовому середовищі.

Тут ми підходимо до детального математичного подання формул і рівнянь, використовуючи вже відомі співвідношення (4) і (8), які виступають законами збереження маси та імпульсу. Однак, для вирішення завдання цього мало, необхідно записати ще одне рівняння:

$E=E_{T}+E_{k}=$ const,

що виражає закон збереження енергії. Енергія вибуху - стала величина і дорівнює сумі двох доданків: потенціальної енергії $E_{T}$ і кінетичної $E_{k}$. Загалом система складається $з$ трьох рівнянь:

$4 \pi R^{2} \Delta r \rho_{1}=\frac{4}{3} \pi R^{3} \rho_{0}$,

$\frac{d}{d t}\left(m u_{1}\right)=4 \pi R^{2} \alpha P_{1}$

$0<R \leq R_{x}^{0} E_{T}+E_{k}=$ const

до яких додається умова сильного вибуху

$M \gg 1$

коли

$u_{1}=\frac{2 D}{\gamma+1}$

i

$P_{1}=\frac{2}{\gamma+1} \rho_{0} D^{2}$

(згадаємо формулу $\frac{P_{1}}{P_{0}}=\frac{2 \gamma M^{2}-\gamma+1}{\gamma+1}[5]$; якщо $M \gg 1$,

$\frac{P_{1}}{P_{0}}=\frac{2 \gamma M^{2}}{\gamma+1}=\frac{2 \gamma \frac{D^{2}}{c_{0}^{2}}}{\gamma+1}=\frac{2 \gamma \frac{D^{2} \rho_{0}}{\gamma P_{0}}}{\gamma+1}=\frac{2 \rho_{0} D^{2}}{P_{0}(\gamma+1)}$,

звідки $\left.P_{1}=\frac{2 \rho_{0} D^{2}}{\gamma+1}\right)$, де $P_{1}-$ тиск на фронті ударної хвилі. Необхідно зазначити, що у поданій системі рівнянь співвідношення (4) не визначає зв'язок 
між областями, розділеними фронтом ударної хвилі (області (0) та (1)), а пов'язує розділений часовим проміжком стан до вибуху і після нього. Розв'язуючи цю задачу для одновимірної центральносиметричної течії, повертаємося до рівняння (8).

Маса сама залежить від часу, тому за часом диференціюється не швидкість, а кількість руху $\left(m u_{1}\right)$. На неї зсередини діє сила $\left(4 \pi R^{2} P_{c}\right)$, оскільки $\left(P_{c}\right)$ прикладається до одиниці поверхні. Сила, що діє ззовні, дорівнює нулю, оскільки початковим тиском газу нехтуємо. Висвітлюючи в рівнянні $(8),\left(u_{1}\right)$ і $\left(P_{1}\right)$ через швидкість фронту $D=d R / d t$ за вже відомими формулами (6), (12), отримуємо нове співвідношення

$\frac{1}{3} \frac{d}{d t} R^{3} D=\alpha D^{2} R^{2}$

Помічаючи, що

$\frac{d}{d t}=\frac{d}{d R} \frac{d R}{d t}=D \frac{d}{d R}$

і інтегруючи рівняння, знаходимо

$D=a R^{-3(1-\alpha)}$,

де $a$ - стала інтегрування. Для визначення величин $(a)$ та $(\alpha)$ використаємо закон збереження енергії. Kiнетична енергія газу така:

$E_{k}=\frac{m u_{1}^{2}}{2}$

Внутрішня енергія зосереджена в "порожнині", обмеженій нашим нескінченно тонким шаром. Тиск у порожнині дорівнює тиску $\left(P_{c}\right)$. Фактично це означає, що не строго вся маса укладена в шарі, у "порожнині" також є невелика кількість речовини. Внутрішня енергія дорівнює:

$E_{T}=\frac{1}{\gamma-1} \frac{4 \pi R^{3}}{3} P_{c}$

(в газовій динаміці питома внутрішня енергія ідеального газу обчислюється як $e=\frac{P}{\rho}\left(\frac{1}{\gamma-1}\right)$, де $P$ - тиск, $\rho$ - щільність, $\gamma-$ показник адіабати), таким чином,

$E=E_{T}+E_{k}=\frac{1}{\gamma-1} \frac{4 \pi R^{3}}{3} P_{c}+\frac{m u_{1}^{2}}{2}$.

Знову висвітливши $\left(P_{c}\right)$ та $\left(u_{1}\right)$ через $(D)$ і підставивши $D=a R^{-3(1-\alpha)}$, отримаємо

$E=\frac{4}{3} \pi \rho_{0} a^{2}\left[\frac{2 \alpha}{\gamma^{2}-1}+\frac{2}{(\gamma+1)^{2}}\right] R^{3-6(1-\alpha)}$.
Оскільки енергія вибуху $(E)$ - константа, показник степеня змінної величини $(R)$ повинен перетворитися на нуль. Це означає, що

$\alpha=\frac{1}{2}$.

Отримане рівняння визначає сталу $(a)$ :

$a=\left[\frac{3}{4 \pi} \frac{(\gamma-1)(\gamma+1)^{2}}{3 \gamma-1}\right]^{1 / 2}\left(\frac{E}{\rho_{0}}\right)^{1 / 2}$.

Підставляючи наявні значення $(a)$ та $(\alpha)$ у формулу (15), знаходимо вираз для швидкості ударної хвилі при точковому вибуху

$D=\left[\frac{3}{4 \pi} \frac{(\gamma-1)(\gamma+1)^{2}}{3 \gamma-1}\right]^{1 / 2}\left(\frac{E}{\rho_{0}}\right)^{1 / 2} R^{-3 / 2}$

або

$D=\xi_{0}\left(\frac{E}{\rho_{0}}\right)^{1 / 2} R^{-3 / 2}$,

де

$\xi_{0}=\left[\frac{3}{4 \pi} \frac{(\gamma-1)(\gamma+1)^{2}}{3 \gamma-1}\right]^{1 / 2}$.

\section{3. Вибух у горючій суміші газів згідно з інтерпретацією автора}

Відмінні риси завдання в тому, що в даному середовищі можливі екзотермічні хімічні реакції, тому цілком логічно припустити безперервність переходу вибухової хвилі у хвилю детонації. Розглянемо деяку модель. Внаслідок вибуху по газу почне поширюватися сильна ударна хвиля, яка нагріє його до стану, за якого можливі реакції горіння. Позначимо енергію вибуху як $\left(E_{0}\right)$. Енергія, що виділилася при згоранні газу, дорівнюватиме $(U)$ :

$U=\frac{4}{3} \pi R_{1}^{3} \rho_{0} Q^{\prime}, \quad R_{0} \ll R_{1}$,

$Q^{\prime}$ - кількість тепла, що виділяється одиничною масою середовища; процес розглядається в момент часу $\left(t_{1}\right)$, коли $R=R_{1}$ (рис. 2 ).

Припускаючи, що $E_{0}>U$, знаходимо умову слабкого впливу енергії детонації на перебіг процесу [6]:

$R_{1}<R_{x}$

де

$R_{x}^{3}=\frac{3 E_{0}}{4 \pi Q^{\prime} \rho_{0}}$. 
Якщо заряд має кінцевий радіус $\left(R_{0}\right)$, то застосовуючи звичайну теорію точкового вибуху до опису руху, необхідно використовувати оцінку

$R_{0}<R<R_{x}$

Треба відзначити, що умови (26) та (27) сильно обмежують сферу застосування законів точкового вибуху в інертному газі до течій детонуючого середовища. Однак, якщо енергія $\left(E_{0}\right)$ велика і виділяється в малому об'ємі, то в області $R_{1}<R_{x}$ процес буде відбуватися, в основному, як при звичайному точковому вибуху. 3 іншого боку, для моменту часу $\left(t_{2}\right)$, коли

$R=R_{2}, \quad E_{0}<U$,

головну роль почнуть відігравати процеси горіння, течія газу матиме основні риси детонаційного горіння [6].

З усього зазначеного вище зробимо деякі цікаві висновки:

1. У горючій суміші газів теорія точкового вибуху застосовується в межах $R_{0}<R<R_{x}$, якщо для даної суміші справедлива викладена вище модель переходу вибухової хвилі в детонацію. Можливий і інший випадок, коли детонація нездійсненна в даних фізикохімічних умовах газового середовища і вибухова хвиля просто згасає. 2 . Коли $R \rightarrow R_{x}, E \neq$ const, енергія системи помітно змінюється, в цілому, майже подвоюється, що треба враховувати, вивчаючи рух газу на даному етапі. 3. Очевидно, якщо $R \rightarrow R_{x}$, то $E \sim R^{3}$ (енергія пропорційна радіусу сфери, піднесеному в куб). Тут натрапляємо на думку, що модель точкового вибуху для горючої суміші газів, коли $R \rightarrow R_{x}$, необхідно видозмінити, або розширити, використовуючи її в наших умовах. Подивимося ще раз формулу, що виражає закон збереження енергії:

$E=\frac{4}{3} \pi \rho_{0} a^{2}\left[\frac{2 \alpha}{\gamma^{2}-1}+\frac{2}{(\gamma+1)^{2}}\right] R^{3-6(1-\alpha)}$.

У теорії точкового вибуху для звичайної суміші, не здатної детонувати, прийнято $E=$ const, тому $\alpha=$ $1 / 2$. Припустимо, що $\alpha=1$, тоді $E \sim R^{3}$, це необхідно для нашого випадку. Як бачимо, закон збереження енергії цілком допускає такий результат:

$\alpha=1$;

$E=\frac{4}{3} \pi \rho_{0} a^{2}\left[\frac{2 \alpha}{\gamma^{2}-1}+\frac{2}{(\gamma+1)^{2}}\right] R^{3}$

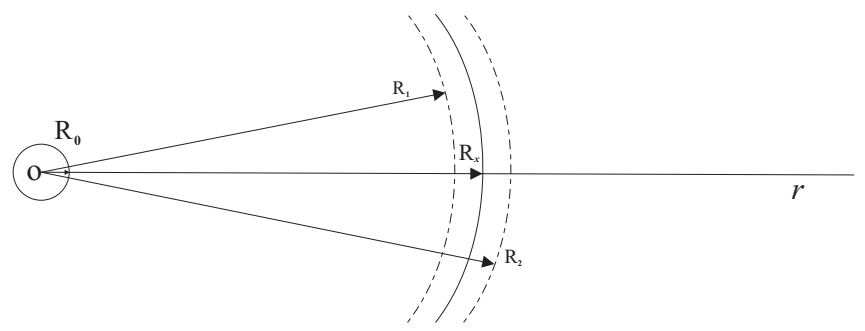

Рис. 2. Безперервний перехід вибухової хвилі у хвилю детонації: $R_{0}$ - радіус заряду; $R_{x}$ - межа можливого переходу сильної детонації в режим Чепмена-Жуге

$a=\left[\frac{3}{16 \pi} \frac{(\gamma-1)(\gamma+1)^{2}}{\gamma}\right]^{1 / 2}\left(\frac{E}{\rho_{0}}\right)^{1 / 2} R^{-3 / 2}$.

Підставляємо нові значення $(a)$ та $(\alpha)$ у формулу $D=$ a $R^{-3(1-\alpha)}$, звідки маємо

$D=a=\left[\frac{3(\gamma-1)(\gamma+1)^{2}}{16 \pi \gamma}\right]^{1 / 2}\left(\frac{E}{\rho_{0}}\right)^{1 / 2} R^{-3 / 2}$.

Згідно з правилами інтегрування, $a$ - стала величина. Таким чином, автор пропонує нову формулу для швидкості вибухової хвилі в реагуючому газовому середовищі:

$D=\left[\frac{3(\gamma-1)(\gamma+1)^{2}}{16 \pi \gamma}\right]^{1 / 2}\left(\frac{E}{\rho_{0}}\right)^{1 / 2} R^{-3 / 2}=$ const

Це цілком можливо, якщо врахувати, що енергія системи змінюється.

\section{4. Результати та їх обговорення}

Спробуємо визначити швидкість ударної хвилі у критичній зоні, коли $R \rightarrow R_{x}$ (рис. 2). Для прикладу розглянемо гримучу суміш

$2 \mathrm{H}_{2}+\mathrm{O}_{2}=2 \mathrm{H}_{2} \mathrm{O}+Q, \quad Q=286,5$ кДж/моль

де $Q$ - тепловий ефект від згорання одного моля водню. У гримучій суміші відбувається ініціація реакції (початковий вибух). Припустимо, енергія системи

$E=V n_{\mathrm{H}_{2}} q+E_{0}$

де $V$ - обсяг деякої сфери; $n_{\mathrm{H}_{2}}$ - концентрація молекул водню в ній; $q$ - тепловий ефект від однієї молекули водню; $E_{0}$ - початкова енергія заряду радіуса $R_{0}$ (нагадаємо $R_{0} \ll R_{x}$, але $R \rightarrow R_{x}, R$ - поточний 
радіус сфери). Обсяг сфери та концентрація водню в ній обчислюються за відомими формулами

$V=\frac{4}{3} \pi R^{3}, \quad n_{\mathrm{H}_{2}}=\frac{P_{0}}{K^{*} T_{0}} N_{A} c_{\%}$,

де $\frac{P_{0}}{K^{*} T_{0}}=\frac{\rho_{0}}{\mu} ; P_{0} ; T_{0} ; \rho_{0}-$ початкові дані про тиск, температуру і щільність газової суміші; $K^{*}$ - універсальна газова стала; $N_{\mathrm{A}}$ - число Авогадро; $c_{\%}-$ коефіцієнт, що показує процентний склад водню, який згоряє (передбачається, що у процесі реакції вигорає весь водень); $\mu$ - молярна маса суміші. Таким чином,

$E=\frac{4}{3} \pi R^{3} \frac{P_{0}}{K^{*} T_{0}} N_{\mathrm{A}} c_{\%} q+E_{0}$.

Підставляючи (35) в (33), отримуємо

$$
\begin{aligned}
& D=\left[\frac{3(\gamma-1)(\gamma+1)^{2}}{16 \pi \gamma}\right]^{1 / 2} \times \\
& \times\left[\frac{4 / 3 \pi R^{3}\left(\frac{P_{0} N_{\mathrm{A}} c_{\%}}{K^{*} T_{0}}\right) q+E_{0}}{\frac{P_{0} \mu}{K^{*} T_{0}}}\right]^{1 / 2} \times \\
& \times R^{-3 / 2}=\xi_{0}^{\prime}\left[\frac{4 / 3 \pi R^{3} N_{\mathrm{A}} q c_{\%}}{\mu}+\frac{E_{0}}{\rho_{0}}\right]^{1 / 2} R^{-3 / 2},
\end{aligned}
$$

де

$$
\xi_{0}^{\prime}=\left[\frac{3(\gamma-1)(\gamma+1)^{2}}{16 \pi \gamma}\right]^{1 / 2} .
$$

Продовжимо наші перетворення,

$D=\left[\frac{(\gamma+1)^{2}(\gamma-1) R^{-3}}{4 \gamma} \frac{R^{3} N_{\mathrm{A}} q c_{\%}}{\mu}+\left(\xi_{0}^{\prime}\right)^{2} \frac{E_{0} R^{-3}}{\rho_{0}}\right]^{1 / 2}=$

$=\left[\frac{(\gamma+1)^{2}(\gamma-1)}{4 \gamma} \frac{N_{\mathrm{A}} q c_{\%}}{\mu}+\left(\xi_{0}^{\prime}\right)^{2} \frac{E_{0}}{\rho_{0} R^{3}}\right]^{1 / 2}$.

У момент часу, коли $R \rightarrow R_{x}$, де $R_{x} \gg R_{0}$; $\left(\xi_{0}^{\prime}\right)^{2} \frac{E_{0}}{\rho_{0} R^{3}} \rightarrow 0$ (другий доданок прямує до нуля); звідси отримаємо

$D=\left[\frac{(\gamma+1)^{2}(\gamma-1)}{4 \gamma} \frac{Q c_{\%}}{\mu}\right]^{1 / 2}$,

врахувавши $Q=N_{\mathrm{A}} q(Q-$ теплова енергія моля водню). Це і є запропонована формула швидкості детонаційної хвилі.
При переході через межу $\left(R_{x}\right)$, енергія заряду $\left(E_{0}\right)$ втрачає свій вплив, далі енергія системи поповнюється тільки за рахунок першого доданка, який показує реальну швидкість хвилі. Якщо формула (37) відповідає дійсності, то досліджувана нами величина не залежить від тиску суміші. У початковий момент ми бачимо сталу швидкість, вона визначається такими параметрами: $Q$ - енергією згорання моля горючого газу; $c_{\%}$ - відсотковим коефіцієнтом згорілого газу; $\mu$ - молярною масою суміші; $\gamma$ - показником адіабати для даної суміші газів. Для плоскої хвилі $[5,7]$ широко відома формула

$D=\sqrt{2\left(\gamma^{2}-1\right) Q^{*}}$,

де $Q^{*}$ - відношення енергії, що виділяється масою речовини до потоку маси даної речовини. У підсумку, порівнюючи формули (37) та (38) приходимо до висновку, що вони дуже схожі, хоча, на наш погляд, формула (37) більш точно відображає суть того, що відбувається, якщо розглядати безперервний процес переходу сферичної детонації у плоску. Результати пропонуються для двох різних газових сумішей у вигляді порівняльної таблиці. У таблиці введено такі позначення: $D_{s}-$ швидкість сферичної хвилі (початок детонації, коли $R=R_{x}$ ); $D_{n}$ - швидкість плоскої хвилі (кінцевий етап детонації, коли $R \rightarrow \infty$ ); $\epsilon$ - різниця між поданими значеннями швидкості, виражена у відсотках $\left(D_{s}-\right.$ обчислюється за новою формулою, $D_{n}$ - літературні дані [8]).

$\mathrm{y}$ роботі розглянуто ідеальний випадок переходу вибухової сферичної хвилі в режим Чепмена-Жуге і тим самим формула (37) доводить можливість існування нормальної сферичної детонації на початку процесу ще задовго до того, як радіус кривизни переходить в нескінченність. Більше того, вона показує можливість існування нормальної сферичної детонації для меншої швидкості ударної хвилі у порівнянні з класичною. Математичний вираз (38) "працює" на кінцевому етапі, коли радіус стає нескінченністю (плоска хвиля). Треба зазначити, що в газовій динаміці часто використовується не швидкість ударної хвилі, а їі відношення до швидкості звуку $\left(c_{0}\right)$ в нерухомому (стаціонарному) газовому середовищі:

$M=\frac{D}{c_{0}}$,

\section{Результати швидкості хвилі}

\begin{tabular}{ccccc}
\hline Газова суміш & $D_{s}, \mathrm{~m} / \mathrm{c}$ & $D_{n}, \mathrm{~m} / \mathrm{c}$ & $\epsilon, \%$ \\
\hline $66,6 \% \mathrm{H}_{2}+33,3 \% \mathrm{O}_{2}$ & 2550 & 2830 & 9,9 \\
$25 \% \mathrm{C}_{2} \mathrm{H}_{2}+75 \% \mathrm{O}_{2}$ & 2089 & 2330 & 10,3 \\
\hline
\end{tabular}


де $M$ - число Маха. Врахуємо формулу швидкості звуку,

$c_{0}=\sqrt{\gamma \frac{P_{0}}{\rho_{0}}}=\sqrt{\gamma \frac{K^{*} T_{0}}{\mu}}$,

i, використовуючи вираз (37), отримуємо

$M=\left[\frac{(\gamma+1)^{2}(\gamma-1)}{4 \gamma^{2}} \frac{Q c_{\%}}{K^{*} T_{0}}\right]^{1 / 2}$

Формула (41) дає залежність числа Маха від: $\gamma$ - коефіцієнта адіабати; $Q$ - теплоти згорання; $c_{\%}$ - процентного коефіцієнта згорілого газу; $T_{0}$ - початкової температури середовища. Змінюючи ці величини, можна регулювати інтенсивність ударного переходу.

\section{5. Висновок}

Якщо відома швидкість ударної хвилі або число Маха, знаходимо вирішення однієї з основних задач газової динаміки, тобто знаходимо параметри $\left(P_{1} ; T_{1} ; \rho_{1}\right)$ на фронті, маючи дані $\left(P_{0} ; T_{0} ; \rho_{0}\right)$ нерухомого середовища. Надалі, ці параметри необхідні для вивчення кінетики хімічної реакції під час ударного переходу. На закінчення необхідно зазначити, що формула (37) дає швидкість детонаційної хвилі на початковому етапі, якщо така народжується при згоранні деякої "порції” $\left(c_{\%}\right)$ горючого газу, коли $R \rightarrow R_{x}$ (див. рис. $2 \mathrm{i}$ модель переходу вибухової хвилі у хвилю детонації). Вона діє для об'ємної сферичної хвилі, на відміну від відомої в літературі формули

$D=\sqrt{2\left(\gamma^{2}-1\right) Q^{*}}$,

яка призначена для плоских хвиль. Відповісти на питання, чи відбувається детонація насправді, можна після вивчення кінетики хімічної реакції під час переходу через межу $\left(R_{x}\right)$. У тому, що стехіометрична суміш водню з киснем породжує детонаційну хвилю, немає ніяких сумнівів, але чи з'являється дана хвиля в 12\%-ній суміші водню - сказати важко. Тут, потрібно розглядати сам механізм реакції.

1. С.Г. Андреев, А.В. Бабкин, Ф.А. Баум, Физика взрыва (Физматлит, Москва, 2004).

2. Л.П. Орленко, Физика взрьва и удара: Учебное пособие (Физматлит, Москва, 2006).

3. Ч. Мейдер, Численное моделирование детонации (Мир, Москва, 1985).
4. Я.Б. Зельдович, Ю.П. Райзер, Физика ударных волн и высокотемпературных гидродинамических явлений (Физматгиз, Москва, 1963).

5. Н.Н. Сысоев, Ф.В. Шугаев, Ударные волны в газах и конденсированных средах (МГУ, Москва, 1987).

6. В.П. Коробейников, Задачи теории точечного взрыва (Наука, Москва, 1985).

7. W. Fickett, Introduction to Detonation Theory (University of California, Berkeley, 1985).

8. Г.Г. Черный, Газовая динамика (Наука, Москва, 1988).

Одержано 15.04.10

ОПРЕДЕЛЕНИЕ СКОРОСТИ ДЕТОНАЦИОННОЙ ВОЛНЫ ВО ВЗРЫВНОЙ ГАЗОВОЙ СМЕСИ

M.M. Полатайко

$\mathrm{P}$ е $з$ ю м е

В научной литературе общеизвестной является формула для скорости плоской детонационной волны. Она выведена из системы уравнений Гюгонио, однако для сферического реактора пользоваться ею затруднительно. Целью работы стало показать возможность реализации положений теории взрыва в реагирующих газовых средах для вывода подобной формулы, используя специальную модель перехода взрывной волны в детонацию. Как и в первом, так и во втором случае - действуют законы сохранения импульса, массы и энергии, поэтому результаты должны были получиться одинаковыми или почти одинаковыми, что и подтвердили расчеты. В итоге, получена формула очень простая в употреблении и более подходящая для изучения предельных процессов объемной детонации.

\section{DETERMINATION OF DETONATION WAVE VELOCITY IN AN EXPLOSIVE GAS MIXTURE}

\section{M.M. Polatayko}

(180, Grushevskyi Str., Nazavyziv 78425,

Nadvirnyanskyi District, Ivano-Frankivsk Region, Ukraine; e-mail: pmm.miron@mail.ru)

S u m m a r y

The well-known formula for the flat detonation wave velocity derived from the Hugoniót system of equations faces difficulties, if being applied to a spherical reactor. A similar formula has been obtained in the framework of the theory of explosion in reacting gas media with the use of a special model describing the transition of an explosive wave in the detonation. The derived formula is very simple, being also more suitable for studying the limiting processes of volume detonation. 